\title{
Enhanced coronary arteriolar contraction to vasopressin in patients with diabetes after cardiac surgery
}

Nicholas Sellke, BS, Alex Kuczmarski, MS, Isabella Lawandy, BS, Victoria L. Cole, BS, Afshin Ehsan, MD, Arun K. Singh, MD, Yuhong Liu, MD, Frank W. Sellke, MD, and Jun Feng, MD, PhD

\section{ABSTRACT}

Objective: Cardioplegic arrest $(\mathrm{CP})$ and cardiopulmonary bypass $(\mathrm{CPB})$ are associated with vasomotor dysfunction of coronary arterioles in patients with diabetes (DM) undergoing cardiac surgery. We hypothesized that DM may up-regulate vasopressin receptor expression and alter the contractile response of coronary arterioles to vasopressin in the setting of $\mathrm{CP} / \mathrm{CPB}$.

Methods: Right atrial tissue samples of patients with DM and without (ND) $(\mathrm{n}=8$ in each group) undergoing cardiac surgery were harvested before and after $\mathrm{CP} / \mathrm{CPB}$. The isolated coronary arterioles $(80-150 \mu \mathrm{m})$ dissected from the harvested right atrial tissue samples were cannulated and pressurized $(40 \mathrm{~mm} \mathrm{Hg})$ in a no-flow state. The changes in diameter were measured with video microscopy. The protein expression/localization of vasopressin 1A receptors (V1A) and vasopressin $1 \mathrm{~B}$ receptors $(\mathrm{V} 1 \mathrm{~B})$ in the atrial tissue were measured by immune-blotting and immunohistochemistry.

Results: The pre-CP/CPB contractile responses of the coronary arterioles to vasopressin were significantly increased post-CP/CPB in both the ND and DM groups. This effect was more pronounced in the vessels from patients in the DM group than that of vessels from patients in the ND group $(P<.05)$. Vasopressininduced contractile response of the coronary arterioles was inhibited in the presence of the specific V1A antagonist SR $49059\left(10^{-7} \mathrm{M}\right)$ in both ND and DM vessels $(P<.05)$. The post-CP/CPB protein levels of $\mathrm{V} 1 \mathrm{~A}$ were significantly increased compared with pre-CP/CPB values in both the ND and DM groups $(P<.05)$, whereas this increase was greater in DM than that of ND $(P<.05)$. Immunohistochemistry staining further indicates that V1B were mainly expressed in the myocardium but not in vascular smooth muscle.

Conclusions: $\mathrm{CP} / \mathrm{CPB}$ and DM are both associated with up-regulation in V1 receptor expression/localization in human myocardium. Vasopressin may induce coronary arteriolar constriction via V1A. This alteration may lead to increased coronary arteriolar spasm in patients with DM undergoing CP/CPB and cardiac surgery. (J Thorac Cardiovasc Surg 2018;156:2098-107)

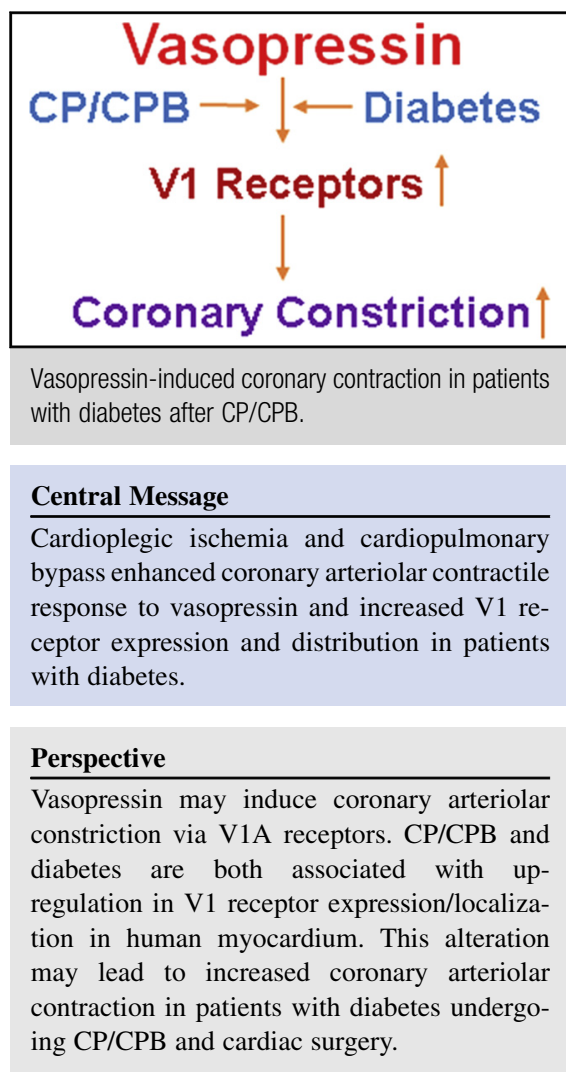

See Editorial Commentary page 2108.
Diabetes (DM) places patients at an increased risk for cardiovascular disease that often progresses more rapidly and is more extensive than in patients without DM (ie,

From the Division of Cardiothoracic Surgery, Department of Surgery, Cardiovascular Research Center, Rhode Island Hospital, Alpert Medical School of Brown University, Rhode Island Hospital, Providence, RI.

This study was supported by the National Heart, Lung, and Blood Institute HL-46716 (F. W. Sellke), HL128831 (F. W. Sellke), and the Institutional Development Award Program Infrastructure for Clinical and Translational Research (IDeA-CTR) grant U54GM115677 (F. W. Sellke). This study was also supported in part by 1R01HL127072 (J. Feng), 1R01HL136347-01 (J. Feng), IDeA from the National Institute of General Medical Science (NIGMS) of the National Institutes of Health (NIH) (5P20-GM103652 [Pilot Project]) (J. Feng), American Heart Association (AHA)-Grant-in-Aid-15GRNT25710105 (J. Feng), Summer Assistantship Award through Basic and Translational Research (BTR) Program (NIH T35HL094308) nondiabetic $[\mathrm{ND}]) .{ }^{1}$ In addition, patients with DM tend to suffer worse outcomes after cardiac surgery, ${ }^{2}$ which may in part be related to vasomotor and endothelial dysfunction

to N. Sellke and A. Kuczmarski, and Summer Research-Early Identification Program (SR-EIP) of the Leadership Alliance at Brown University (NIHR25HL088992) (V. L. Cole).

Received for publication Dec 27, 2017; revisions received April 10, 2018; accepted for publication May 13, 2018; available ahead of print July 26, 2018.

Address for reprints: Jun Feng, MD, PhD, Division of Cardiothoracic Surgery, Rhode

Island Hospital, 1 Hoppin St, Coro West Room.5.229, Providence, RI 02903

(E-mail: jfeng@lifespan.org).

$0022-5223 / \$ 36.00$

Copyright (c) 2018 by The American Association for Thoracic Surgery

https://doi.org/10.1016/j.jtcvs.2018.05.090 

Abbreviations and Acronyms

$\begin{array}{rlrl}\mathrm{CP} & = & \text { cardioplegia } \\ \mathrm{CPB} & = & \text { cardiopulmonary bypass } \\ \mathrm{DM} & = & \text { diabetes } \\ \mathrm{HbA1C} & = & \text { hemoglobin A1C } \\ \mathrm{ND} & = & \text { pondiabetic } \\ \mathrm{PBS} & = & \text { after cardioplegia and } \\ \text { post-CP/CPB } & \text { cardiopulmonary bypass } \\ \text { post-CP/CPB-DM }= & \text { after cardioplegia and } \\ & \text { cardiopulmonary bypass in } \\ & \text { patients with diabetes } \\ \text { post-CP/CPB-ND }= & \text { after cardioplegia and } \\ & \text { cardiopulmonary bypass in } \\ & \text { patients without diabetes } \\ \text { pre-CP/CPB } & \text { before cardioplegia and } \\ & \text { cardiopulmonary bypass } \\ \text { pre-CP/CPB-DM }= & \text { before cardioplegia and } \\ & \text { cardiopulmonary bypass in } \\ & \text { patients with diabetes } \\ \text { pre-CP/CPB-ND }= & \text { before cardioplegia and } \\ & \text { cardiopulmonary bypass in } \\ & \text { patients without diabetes } \\ \mathrm{V} 1 \mathrm{~A} & =\text { vasopressin 1A receptor } \\ \mathrm{V} 1 \mathrm{~B} & \text { vasopressin 1B receptor } \\ & \end{array}$

Scanning this QR code will take you to a supplemental video for the article.

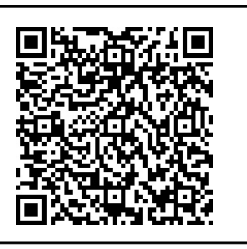

in arteries and arterioles. ${ }^{3-8}$ The mechanism resulting in this microvascular dysfunction is not completely understood, but may be related to an altered response to vasopressin. ${ }^{9-11}$

Previous work has demonstrated that myocardial ischemia is associated with a marked increase in the contractile response of coronary microvasculature to vasopressin in the left ventricular myocardium of dogs. ${ }^{11}$ Interestingly, large epicardial coronary arterial rings responded minimally to vasopressin, and this was not significantly altered by ischemia or reperfusion. ${ }^{11}$ Circulating levels of vasopressin are elevated after myocardial ischemia and other stresses, ${ }^{12}$ exemplifying the important role of vasopressin on vascular tone. Indeed, vasopressin is still used clinically as a first-line drug to increase vascular tone for maintaining systemic blood pressure after cardiac surgery ${ }^{13}$ and to decrease mesenteric blood flow in the setting of gastrointestinal hemorrhage. ${ }^{14}$ Few studies have examined the altered effects of vasopressin or the expression/localization of the vasopressin receptors in the human coronary microvasculature.

In fact, to our knowledge, no such studies in patients have been conducted in response to cardioplegia (CP) and cardiopulmonary bypass (CPB) in the setting of DM. We hypothesized that DM up-regulates the vasopressin receptor expression and alters the contractile response of coronary arterioles to vasopressin in the setting of $\mathrm{CP} / \mathrm{CPB}$. We first examined whether DM alters the human coronary arteriolar response to vasopressin using an in vitro microvessel preparation. We then measured the effect of DM and $\mathrm{CP} / \mathrm{CPB}$ on vasopressin receptor expression/localization in coronary arterioles and myocardium using Western blotting and immunohistochemistry.

\section{METHODS \\ Human Subjects and Tissue Harvesting}

Two sequential tissue samples were harvested from the right atrial appendage of patients undergoing a coronary artery bypass grafting procedure. The surgeons used a double purse-string technique with 3-0 polypropylene sutures on the right atrial appendage. The first specimen (before cardioplegia and cardiopulmonary bypass [pre-CP/CPB] tissue sample) was taken during initial atrial cannulation and before tightening the superior suture to secure the cannula. Then, the inferior suture remained loose throughout the procedure, enough to allow the respective atrial section to be exposed to the $\mathrm{CP}$ solution during cardioplegic arrest and subsequently reperfused once the aortic crossclamp was removed. The second specimen (after cardioplegia and cardiopulmonary bypass [post-CP/CPB]) was harvested after removal of crossclamp and atrial cannula. Thus, the atrium was exposed to the effects of $\mathrm{CP} / \mathrm{CPB}$ and a brief period of reperfusion (approximately 5-10 minutes). The harvesting procedure has been described in detail. ${ }^{4-6,10,15}$ Harvested tissue was either frozen in liquid nitrogen (immunoblotting), fixed in $10 \%$ formalin for 24 hours followed by paraffinization and sectioning into $5-\mu \mathrm{m}$ slices (immunofluorescent staining), or stored in cold Krebs buffer (in vitro analysis).

Using hemoglobin A1C (HbA1C) and their medical history, we divided qualified patients into 2 groups: (1) patients with a normal $\mathrm{HbA1C}(<6.5)$ and no documented history of DM were placed in the ND group and (2) patients with a $\mathrm{HbA} 1 \mathrm{C}$ equal to or greater than 8.5 were placed in the DM group. If a patient had a HbA1C between 6.5 and 8.5, they were excluded. Patients who experienced an aortic crossclamp time longer than $120 \mathrm{mi}-$ nutes or a CPB time longer than 180 minutes were also excluded from the study. Each group contained 8 patients. All procedures were approved by the institutional review board of Rhode Island Hospital and Brown Medical School, and informed consent was obtained from all enrolled patients as required by the institutional review board.

\section{Cold Blood Cardioplegic Solution}

Cold blood CP solution $\left(4^{\circ} \mathrm{C}-8^{\circ} \mathrm{C}\right)$ consisted of a 4:1 mixture of oxygenated blood and hyperkalemic crystalloid CP solution (CAPS, Lanham, $\mathrm{Md})$. An initial 600 to $1000 \mathrm{~mL}$ (introduction) of cold-blood $\left(4^{\circ} \mathrm{C}-8^{\circ} \mathrm{C}\right)$ hyperkalemic $\left(\mathrm{K}^{+} 25 \mathrm{mmol} / \mathrm{L}\right) \mathrm{CP}$ solution was delivered antegrade into the aortic root, followed by 200 to $500 \mathrm{~mL}\left(\mathrm{~K}^{+} 8 \mathrm{mmol} / \mathrm{L}\right.$, maintenance) of cold blood CP solution every 15 to 20 minutes.

\section{In Vitro Analysis}

Coronary arterioles (90-150 $\mu \mathrm{m}$ internal diameters) were dissected from the atrial myocardium using a 10 to $60 \times$ dissecting microscope. ${ }^{4-6,16}$ Microvessels were placed in the microvessel chamber and cannulated using dual glass micropipettes (40-80 $\mu \mathrm{m}$ in diameter) and then secured 
with 10-0 nylon monofilament sutures. Oxygenated ( $95 \%$ oxygen and $5 \%$ carbon dioxide) Krebs buffer solution warmed to $37^{\circ} \mathrm{C}$ was continuously circulated through the microvessel chamber and reservoir. The microvessels were pressurized to $40 \mathrm{~mm} \mathrm{Hg}$ in a no-flow state with a burette manometer filled with a Krebs buffer solution. An inverted microscope (40 to $200 \times$, Olympus CK2; Olympus Optical, Tokyo, Japan) connected to a video camera was used to project the vessel image onto a monitor. The internal luminal diameter was observed using an electronic dimension analyzer. Vessels were bathed in the organ chamber for at least 30 minutes before being subjected to a pharmacologic intervention. ${ }^{4-6}$ Vasopressin $\left(10^{-8}-10^{-5} \mathrm{M}\right)^{9,11,17}$ with or without SR 49059, a selective vasopressin $1 \mathrm{~A}$ receptors (V1A) receptor antagonist $\left(10^{-7} \mathrm{M}\right)$, was applied to the vessel and the response was measured.

\section{Immunoblotting}

Right atrial tissue samples harvested from 6 patients per group were dissected and cleaned of connective tissues, then placed in sodium dodecyl sulfate polyacrylamide gel electrophoresis buffer. Total protein $(40 \mu \mathrm{g})$ was fractionated on an $8 \%$ to $16 \%$ sodium dodecyl sulfate polyacrylamide gel electrophoresis gel and then transferred to a polyvinylidene difluoride membrane (Millipore Corporation, Bedford, Mass). The membranes were incubated for 1 hour in 1:1000 dilutions of individual primary antibodies to Anti-V1A and vasopressin 1B receptor (V1B) (Abcam, Cambridge, Mass) at room temperature. The detailed methods have been described previously. ${ }^{4-6}$

\section{Immunoperoxidase Staining of V1A Receptors}

Atrial myocardial tissue sections ( $\mathrm{n}=5$ /group) from ND and DM groups were deparaffinized in xylene and rehydrated in graded ethanol and phosphate-buffered saline (PBS) solution. The sections were incubated in $3 \% \mathrm{H}_{2} \mathrm{O}_{2}$ for 20 minutes. The section was then incubated with anti-V1A antibody $(1 \mathrm{mg} / \mathrm{mL})$ for 60 minutes at room temperature and washed with PBS. The sections were then incubated with biotinylated secondary antibody (Vector Laboratories, Burlingame, Calif). The chromogen 3,30diaminobenzidine was then used. Atrial tissue was visualized using a Nikon E800 microscope system (Nikon, Melville, NY). Six image photos per slide were taken at the same magnification resolution $(\times 20)$ for optical density (intensity) analysis (Spot RT3; Diagnostic Instruments, Sterling Heights, Mich).

\section{Immunofluorescence}

Atrial tissue sections from 5 patients per group were first deparaffinized in xylene then rehydrated using graded ethanol and PBS solutions. The antigen was unmasked using sodium citrate $(10 \mathrm{mmol} / \mathrm{L}, \mathrm{pH}=6.0)$, followed by a PBS wash and blocking with $2 \%$ bovine serum albumin in PBS at room temperature for 2 hours. ${ }^{4-6}$ After PBS wash, sections were incubated overnight with anti-V1A and V1B antibodies (each used at 1:200) (Abcam) and smooth muscle actin antibody at a temperature of $4^{\circ} \mathrm{C}$. Sections were then washed in PBS and incubated with the appropriate Alexa-fluor secondary antibodies and mounted using fluorescent mounting medium (Vector Labs, Burlingame, Calif). Tissue was visualized using a Zeiss LSM510 confocal microscope system (Carl Zeiss MicroImaging, Inc, Thornwood, NY). Tissue labeled with only the actin antibody and secondary antibody served as a negative control.

\section{Chemicals}

Vasopressin and SR49059 were obtained from Sigma-Aldrich (St Louis, Mo) and dissolved in ultrapure distilled water on the day of the study.

\section{Data Analysis}

Data are presented as the mean and standard deviation. Categorical data of patient characteristics were analyzed with the Fisher exact test, and the other clinical data were analyzed with the paired Student $t$ test. Microvascular responses are expressed as percent contraction of the baseline diameter. Microvascular data of vasopressin dose-responses were analyzed using 2-way repeated-measures analysis of variance followed by the Bonferroni multiple comparisons test. The data of immunohistochemistry and Western blot were analyzed using one-way analysis of variance followed by Bonferroni multiple comparisons test or Newman-Keuls multiple comparisons test. $P$ values $<.05$ were considered significant (GraphPad Software, Inc, San Diego, Calif).

\section{RESULTS \\ Patient Characteristics}

Patient characteristics are listed in Table 1. All patients (8/group) were on aspirin and $\beta$-blockers, and patients with preoperative hypertension were on antihypertensive medication. The preoperative HbA1C level averaged $8.9 \pm 0.45$ in patients in the DM group and $5.3 \pm 0.3$ in patients with the ND group.

\section{Microvascular Contraction to Vasopressin}

There were no significant differences in microvessel diameters among subgroups at baseline before vasopressin treatment (Table 2). Vasopressin induced dose-dependent contractile responses in the microvessels of all studied groups (Figure 1, $A$ and Figure 2, $A$ and $C$ ). There were no significant differences in the dose-dependent contractile response to vasopressin between the pre-CP/CPB-ND (before cardioplegia and cardiopulmonary bypass in patients without diabetes) and pre-CP/CPB-DM (before cardioplegia and cardiopulmonary bypass in patients with diabetes) groups $(P=.45$, Figure $1, A)$. In contrast, the dose-dependent responses to vasopressin were significantly increased after cardioplegia and cardiopulmonary bypass in patients without diabetes (post-CP/CPB-ND) and after cardioplegia and cardiopulmonary bypass in patients with diabetes (post-CP/CPB-DM) compared with its pre-CP/ CPB-ND or pre-CP/CPB-DM at tested concentrations of $10^{-7} \mathrm{M}, 10^{-6} \mathrm{M}$, and $10^{-5} \mathrm{M}$, respectively $(* P<.05$, vs pre-CP/CPB-ND, or pre-CP/CPB-DM, Figure 1, A). This increased dose-dependent response was more pronounced in the post-CP/CPB-DM vessels than that of post-CP/ CPB-ND vessels at $10^{-7} \mathrm{M}, 10^{-6} \mathrm{M}$, and $10^{-5} \mathrm{M}$, respectively ( ${ }^{\#} P<.05$, vs post-CP/CPB-ND, Figure $1, A$ ). In particular, the contractile responses of the pre-CP/CPBND coronary arterioles to vasopressin $\left(10^{-5} \mathrm{M}\right)$ were significantly increased post-CP/CPB-ND $(* P=.0001$, vs pre-CP/CPB-ND, Figure 1, B) and post-CP/CPB-DM $(* P=.0001$ vs pre-CP/CPB-DM, Figure $1, B)$ with significant, more pronounced effects in the DM vessels than in the ND group ( ${ }^{\sharp} P=.0001$ vs post-CP/CPB-ND, Figure $\left.1, B\right)$.

\section{Effect of V1 Receptor Antagonist}

Vasopressin-induced dose-dependent (at $10^{-7} \mathrm{M}$, $10^{-6} \mathrm{M}$, and $10^{-5} \mathrm{M}$ ) contractile responses of the coronary arterioles were significantly inhibited in the presence of the 
TABLE 1. Patient characteristics

\begin{tabular}{|c|c|c|c|}
\hline Patient characteristics & ND & DM & $P$ value \\
\hline Age, $y^{*}$ & $65 \pm 7$ & $67 \pm 6$ & .64 \\
\hline Male/female, $n$ & $5 / 3$ & $6 / 2$ & .96 \\
\hline $\mathrm{HbA} 1 \mathrm{c}, \% *$ & $5.3 \pm 0.3$ & $8.9 \pm 0.45$ & .0001 \\
\hline Patient blood glucose, $\mathrm{mg} / \mathrm{dL}$, pre-CP/CPB* & $106 \pm 14$ & $210 \pm 21$ & .0001 \\
\hline Patient blood glucose, $\mathrm{mg} / \mathrm{dL}$, during-CP/CPB* & $140 \pm 20$ & $184 \pm 16$ & .01 \\
\hline Preoperative insulin, $\mathrm{n}$ & 0 & 8 & .001 \\
\hline Intraoperative insulin, $\mathrm{n}$ & 2 & 8 & .002 \\
\hline Hypercholestesterolemia, $n$ & 6 & 7 & .52 \\
\hline Oral hypoglycemic drugs & 0 & 8 & .005 \\
\hline Obesity (BMI > 30) & 4 & 6 & .59 \\
\hline Aspirin & 8 & 8 & .78 \\
\hline Hypertension, $\mathrm{n}$ & 7 & 8 & .86 \\
\hline Atrial fibrillation, $\mathrm{n}$ & 0 & 0 & 1.0 \\
\hline Duration of $\mathrm{CPB}, \mathrm{min} *$ & $112 \pm 20$ & $116 \pm 23$ & .79 \\
\hline Crossclamp time, $\min ^{*}$ & $90 \pm 8$ & $98 \pm 19$ & .70 \\
\hline CABG & 8 & 8 & 1.0 \\
\hline
\end{tabular}

$N D$, Nondiabetic; $D M$, diabetes; $H b A l c$, hemoglobin A1C; $C P$, cardioplegia; $C P B$, cardiopulmonary bypass; $B M I$, body mass index; $C A B G$, coronary artery bypass grafting *Mean \pm standard deviation.

specific V1A antagonist SR $49059\left(10^{-7} \mathrm{M}\right)$ in both ND and DM vessels $(* P<.0001$ vs pre-CP/CPB-ND alone, or preCP/CPB-DM alone, Figure $2, A ; * P<.0001$, vs post-CP/ CPB-ND alone or post-CP/CPB-DM alone, Figure 2, $C$ ). In particular, the contractile responses of vasopressin at $10^{-5} \mathrm{M}$ were significantly diminished in the presence of SR49059 $\left(10^{-7} \mathrm{M}\right)$ in all studied vessels of ND and DM ${ }^{*} P=.0002$ vs pre-CP/CPB-ND alone; ${ }^{*} P<.0001$ vs pre-CP/CPB-DM alone, Figure $2, B ; * P<.0001$ vs post$\mathrm{CP} / \mathrm{CPB}-\mathrm{ND}$ alone; $* P<.0001$ vs post-CP/CPB-DM alone, Figure 2, $D$ ).

\section{Vasopressin Receptor Expression}

There were no significant differences in the protein expression of the V1A receptors before $\mathrm{CP} / \mathrm{CPB}$ between patients in the ND and DM groups $(P=.65$ vs pre-CP/ CPB-ND, Figure 3, $A$ and $C$ ). The post-CP/CPB protein levels of V1A receptors were significantly increased compared with pre-CP/CPB values in both the ND and DM groups $(* P=.04$ vs pre-CP/CPB-ND or $* P=.001$ vs pre-CP/CPB-DM, Figure $3, A$ and $C$ ). This increase was significantly greater in post-CP/CPB-DM than in the post-CP/CPB-ND $(P=.03$, Figure $3, C)$. There were no significant differences in the $\mathrm{V} 1 \mathrm{~B}$ receptor protein expression between the pre-CP/CPB-ND and pre-CP/CPB-DM groups $(P=.9$, pre-CP/CPB-DM, Figure $3, B$ and $D)$ or between pre- and post-CP/CPB-ND ( $P=.9$ vs pre-CP/CPB-ND, Figure $3, B$ and $D$ ). In contrast, the post-CP/CPB-DM protein levels of V1B receptors in the DM myocardium were significantly greater than those of pre-CP/CPB-DM $(* P=.02$, Figure $3, B$ and $D)$ or post-CP/CPB-ND $\left({ }^{\#} P=.01\right.$, Figure $\left.3, D\right)$.

\section{Immunolocalization of V1 Receptors}

Immunohistochemistry staining indicates that the V1A receptors were expressed in atrial microvessels (red arrow,

TABLE 2. Baseline microvessel diameters (in micrometers)

\begin{tabular}{llr}
\hline & Microvessels & \\
\hline pre-CP/CPB-ND $(114 \pm 24)$ & pre-CP/CPB-DM $(122 \pm 22)$ & .4984 \\
post-CP/CPB-ND $(117 \pm 20)$ & post-CP/CPB-DM $(115 \pm 21)$ & .5256 \\
pre-CP/CPB-ND $(114 \pm 24)$ & post-CP/CPB-ND $(117 \pm 20)$ & .7899 \\
pre-CP/CPB-ND $(114 \pm 24)$ & post-CP/CPB-DM $(115 \pm 21)$ & .9306 \\
pre-CP/CPB-DM $(122 \pm 22)$ & post-CP/CPB-DM $(115 \pm 21)$ & .8481 \\
\hline
\end{tabular}

Mean \pm standard deviation, $\mathrm{n}=8$ /group. pre- $C P / C P B-N D$, Before cardioplegia and cardiopulmonary bypass in patients without diabetes; pre-CP/CPB-DM, before cardioplegia and cardiopulmonary bypass in patients with diabetes; post-CP/CPB-ND, after cardioplegia and cardiopulmonary bypass in patients without diabetes; post-CP/CPB-DM, after cardioplegia and cardiopulmonary bypass in patients with diabetes. 


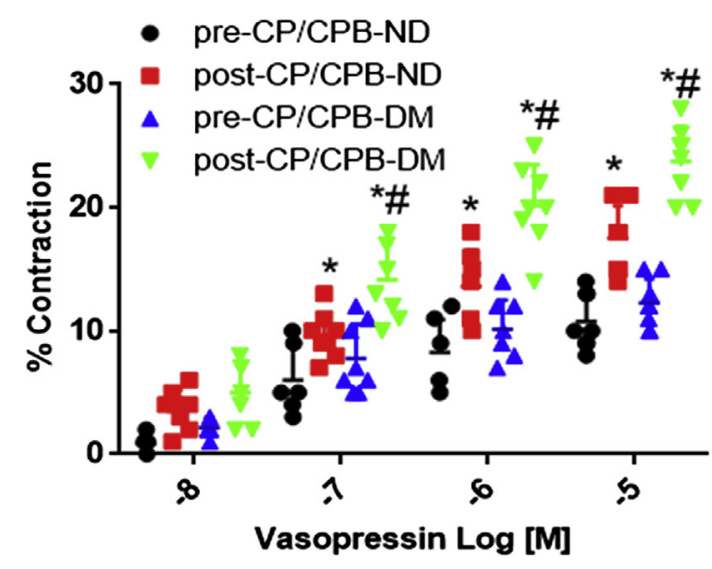

A

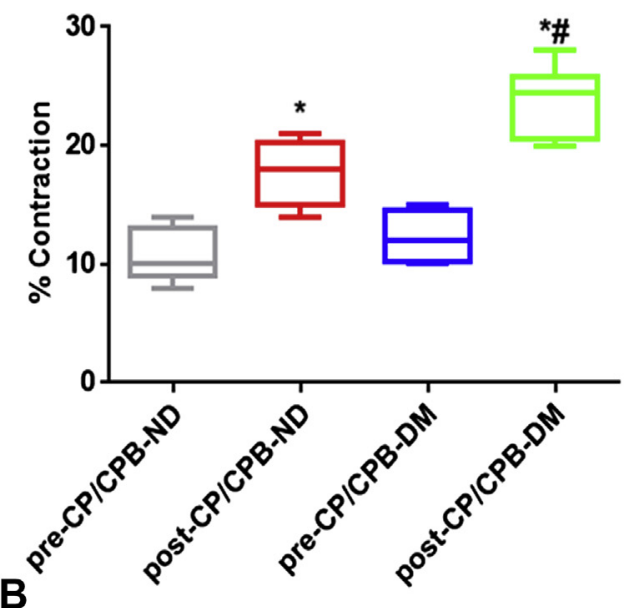

FIGURE 1. A, Dose-dependent contractile response of coronary arterioles to vasopressin $\left(10^{-8}-10^{-5} \mathrm{M}\right)$ from patients in the nondiabetic group before cardioplegia and cardiopulmonary bypass (pre-CP/CPB- $N D$ ) and post-CP/CPB-ND and from patients in the diabetes group pre-CP/CPB-DM and postCP/CPB-DM. B, The bar graph shows the coronary arteriolar contractile response to vasopressin at $10^{-5} \mathrm{M}$. ${ }^{*} P<.05$ versus pre-CP/CPB-ND, ${ }^{\#} P<.05$ versus post-CP/CPB-ND; $\mathrm{n}=8$ /group, mean \pm standard deviation. post-CP/CPB-ND, After cardioplegia and cardiopulmonary bypass in patients without diabetes; pre-CP/CPB-DM, before cardioplegia and cardiopulmonary bypass in patients with diabetes; post-CP/CPB-DM, after cardioplegia and cardiopulmonary bypass in patients with diabetes.

Figure $4, A$ ) and myocardium (brown, Figure $4, A$ ). The intensities of V1A tended to be increased in the pre-CP/CPBDM myocardium compared with pre-CP/CPB-ND (Figure $4, A$ ) but failed to reach statistical significance $(P=.06$, Figure $4, B)$. The pre-CP/CPB V1A levels also tended to be increased post-CP/CPB in both the ND $(P=.18$ vs pre-CP/CPB-ND) and DM groups $(P=.34$, Figure $4, B)$. V1B receptors were mainly expressed in the myocardium (red, Figure 4,C), but not in vascular smooth muscle (green, smooth muscle alpha actin staining, Figure $4, C$ ). The intensities of V1B pre-CP/CPB-DM (Figure $4, D$ ) tended to be increased in the DM myocardium but once again failed to reach statistical significance compared with pre-CP/CPB-ND $(P=.12$, Figure $4, D)$. There were no significant differences in V1B distribution between pre- and post-CP/CPB-ND in the ND group $(P=.3$, Figure $4, C$ and $D)$. In contrast, the pre-CP/CPBDM levels of V1B were significantly increased post-CP/ CPB-DM in the atrial myocardium of patients with DM $\left({ }^{*} P=.001\right.$ vs pre-CP/CPB-DM; ${ }^{\#} P=.0001$ vs post-CP/ CPC-ND, Figure 4, $C$ and $D$ ).

\section{DISCUSSION}

In our study of the coronary arteriolar reactivity in response to vasopressin, the main findings are as follows: (1) the contractile response to vasopressin after $\mathrm{CP} / \mathrm{CPB}$ in patients with the poorly controlled DM was significantly more intense than in the patients in the ND group; (2) there is a minimal contractile response to vasopressin after the addition of the V1A receptor antagonist, SR49059; (3) expression of V1A receptor protein was increased after $\mathrm{CP} / \mathrm{CPB}$ for both patients in the ND and DM groups and was significantly increased in post-CP/CPB in patients in the DM group compared with patients in the ND group; (4) V1B expression was increased in DM post-CP/CPB; and (5) V1B receptor distribution was increased in atrial myocardium in patients in the DM group post-CP/CPB but not in vascular smooth muscle, which expresses few, if any, V1B receptors.

Vasopressin is produced in the posterior pituitary gland. Circulating levels of vasopressin are known to be increased at the beginning of septic shock and reduced in the later stages. ${ }^{18}$ After cardiac surgery, circulating levels of vasopressin are either diminished or increased. ${ }^{19,20}$ Vasopressin may be elevated during hemorrhagic shock, hypotension, acidosis, and hypoxia. ${ }^{21,22}$ Although the administration of vasopressin has been advocated as a first-line drug for the treatment of postcardiac surgical vasoplegia, ${ }^{20,22}$ the use of vasopressin in the setting of ischemic heart disease is associated with increased mortality. ${ }^{23,24}$ Thus, the use of vasopressin to support vasomotor tone in the setting of cardiac surgery has potential implications on the perfusion of the myocardium. The concentration of vasopressin we used in the current study was based on the previous in vitro vessel studies in dogs,${ }^{11}$ pigs, ${ }^{9}$ and humans. ${ }^{17}$ In a preliminary study, in the setting of CP/CPB, we observed that the change in the contractile response of human skeletal muscle arterioles to vasopressin was 

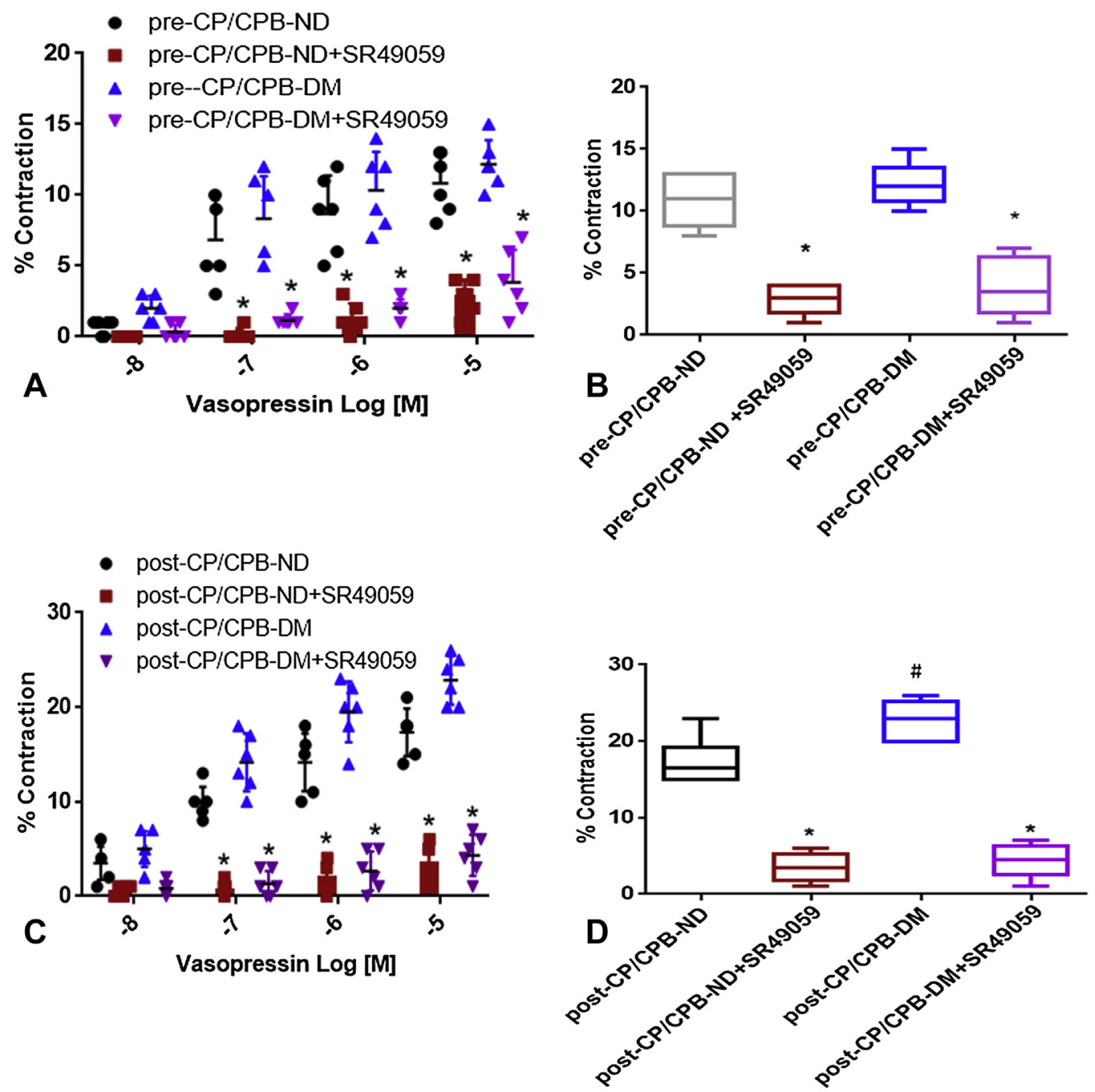

FIGURE 2. A, Dose-dependent contractile response of atrial coronary arterioles to vasopressin in the presence or absence of V1 receptor blocker SR490099 $\left(10^{-7} \mathrm{M}\right)$ in the pre-CP/CPB-ND and the pre-CP/CPB-DM subgroups; B, the coronary arteriolar contractile response to vasopressin at $10^{-5} \mathrm{M}$ in the presence or absence of SR490099 $\left(10^{-7} \mathrm{M}\right)$ in the pre-CP/CPB-ND and the pre-CP/CPB-DM subgroups; C, dose-dependent contractile response of atrial coronary arterioles to vasopressin in the presence or absence of V1 receptor blocker SR490099 $\left(10^{-7} \mathrm{M}\right)$ in the post-CP/CPB-ND and the post-CP/CPB-DM subgroups; D, the coronary arteriolar contractile response to vasopressin at $10^{-5} \mathrm{M}$ in the presence or absence of SR490099 in the post-CP/CPB-ND and the post-CP/CPB-DM subgroups; $* P<.05$ versus pre-CP/CPB-ND alone or $\# P<.05$ versus pre-CP/CPB-DM alone, $\mathrm{n}=6 /$ group, mean \pm standard deviation. pre- $C P / C P B-N D$, Before cardioplegia and cardiopulmonary bypass in patients without diabetes; pre- $C P / C P B-D M$, before cardioplegia and cardiopulmonary bypass in patients with diabetes; post-CP/CPB-ND, after cardioplegia and cardiopulmonary bypass in patients without diabetes; post-CP/CPB-DM, after cardioplegia and cardiopulmonary bypass in patients with diabetes.

opposite from that observed in coronary microvasculature, but occurred at similar concentrations, suggesting that the concentrations we examined have clinical relevance.

Studies in animals and humans have shown that DM results in greater levels of plasma vasopressin ${ }^{25}$ and decreased levels of V1 receptors in the liver and kidney of rats with type $1 \mathrm{DM}^{26}$ In this study, we hypothesized that the coronary microvascular response to vasopressin would be increased after $\mathrm{CP} / \mathrm{CPB}$, and that the up-regulation of vasopressin receptors is greater in patients with $\mathrm{DM}$, and this may in part be responsible for the altered coronary arteriolar contractile response to vasopressin in the setting of $\mathrm{CP} / \mathrm{CPB}$. This study suggests that the increase in coronary arteriolar contractile response in patients post-CP/CPB could be the result of increased expression of V1A receptor proteins and increased distribution of the receptors in the atrial tissue. In the patients with DM, this mechanism is augmented significantly. In the atrial myocardium from 

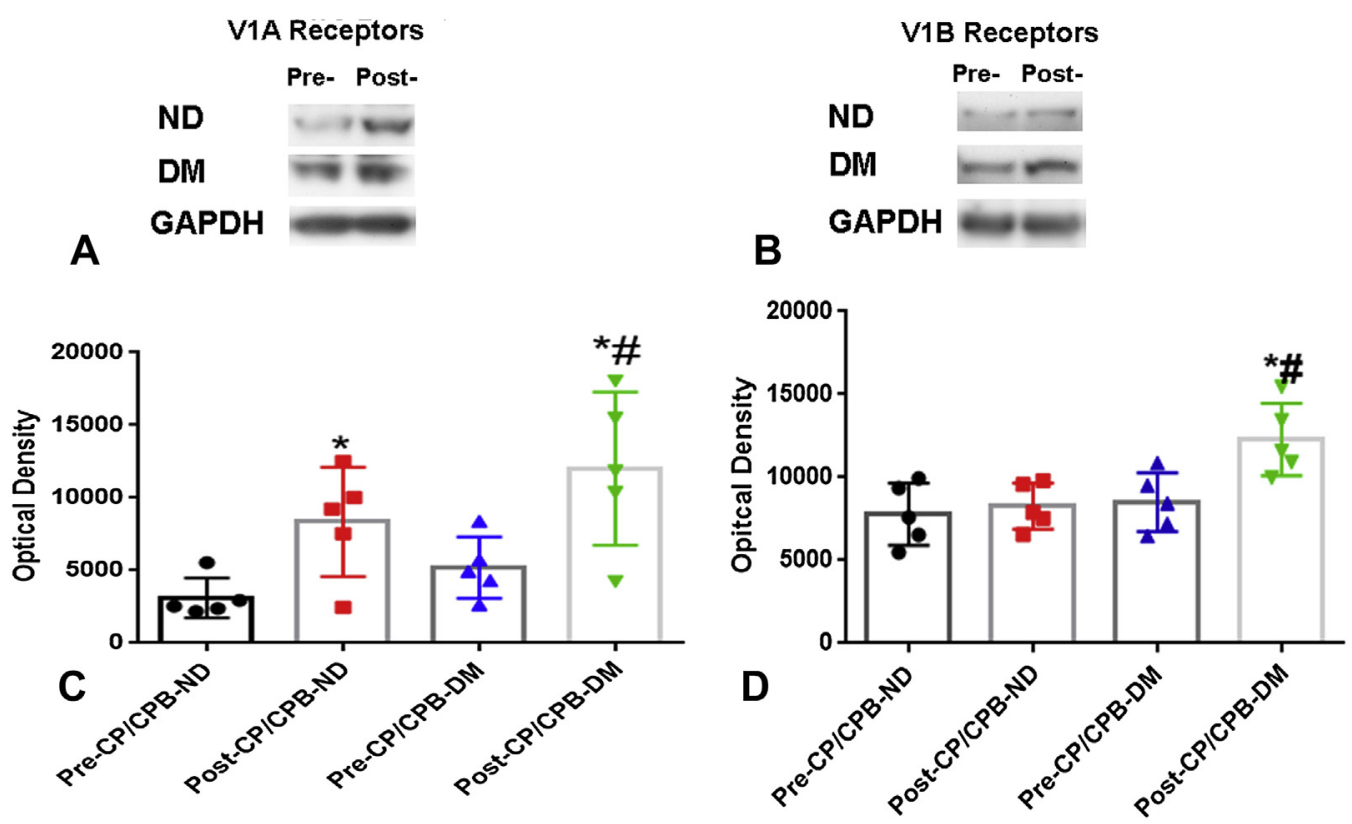

FIGURE 3. $\mathrm{A}$ and $\mathrm{B}$, Representative immunoblots of atrial tissue lysates for $\mathrm{V} 1 \mathrm{~A}$ and $\mathrm{V} 1 \mathrm{~B}$, harvested from patients in the DM and ND groups pre- and post-CP/CPB. C, Immunoblot quantification shows significantly increased V1A expression post-CP/CPB-ND and post-CPB-DM; $* P<.05$ versus pre-CP/ CPB-ND or pre-CP/CPB-DM, ${ }^{\#} P<.05$ versus post-CP/CPB-ND; D, immunoblot quantification shows significantly increased V1B receptor expression post$\mathrm{CP} / \mathrm{CPB}-\mathrm{DM},{ }^{*} P<.05$ versus pre-CP/CPB-ND or pre-CP/CPB-DM, ${ }^{\#} P<.05$ versus post-CP/CPB-ND, $\mathrm{n}=6 /$ group, mean \pm standard deviation. $V 1 A$, Vasopressin 1A receptor; $N D$, nondiabetic; $D M$, diabetes; $G A P D H$, glyceraldehyde-3-phosphate dehydrogenase; $V 1 B$, vasopressin $1 \mathrm{~B}$ receptor; pre-CP/ $C P B-N D$, before cardioplegia and cardiopulmonary bypass in patients without diabetes; post-CP/CPB-ND, after cardioplegia and cardiopulmonary bypass in patients without diabetes; pre-CP/CPB-DM, before cardioplegia and cardiopulmonary bypass in patients with diabetes; post-CP/CPB-DM, after cardioplegia and cardiopulmonary bypass in patients with diabetes.

patients with DM, we also observed a significant increase in $\mathrm{V} 1 \mathrm{~B}$ receptors after $\mathrm{CP} / \mathrm{CPB}$, but this increase was not seen in the vascular smooth muscle.

Our group and others have extensively studied the effect of $\mathrm{CP} / \mathrm{CPB}$ on microvascular reactivity, permeability, neurocognitive decline, and other effects. ${ }^{4-7,27-29}$ Most of the vascular effects result in a diminished response to vasoconstrictor agents such as phenylephrine, endothelin1 , and thromboxane- $\mathrm{A}_{2}$ or endothelium-dependent vasodilator agonists such as substance $\mathrm{P}^{4-6,8,29}$ Two exceptions to this are the increased coronary contractile response observed to serotonin ${ }^{10,15}$ and now the response to vasopressin. The diminished contractile responses to many vasoconstrictors are due in large part to damage to the downstream contractile mechanism, including mitogen-activated protein kinase and protein kinase $\mathrm{C},{ }^{30}$ altered relaxation mechanisms related to increased oxidative stress, ${ }^{31}$ oxygen-derived free radicals, ${ }^{32}$ neutrophilrelated mechanisms, ${ }^{33}$ and receptor desensitization. ${ }^{34}$ The increase in vasopressin receptor expression and responsiveness likely has to do with tissue ischemia/reperfusion and increased oxidative stress. Cell cultured experiments studying the cellular response to oxidative stress, and hypoxia, may be conducted in the future to determine the specifics mechanisms responsible for the observed increased contraction to vasopressin.

\section{Limitations}

Our study does have several possible limitations. First, we did not include patients with well-controlled DM. However, previous studies ${ }^{6,31}$ have shown that vascular responses in patients with controlled DM have less endothelial dysfunction than that observed in vessels from patients with poorly controlled DM. Indeed, most vascular responses in patients with well-controlled DM tend to be very similar to that observed in vessels from patients who are ND. Second, we did not examine mechanisms causing the observed effects. However, even though sample size is small, the groups were fairly well matched. Thus, any difference in response to vasopressin must have been due to DM or some factors related to it. These factors could include chronic hyperglycemia, increased oxidative stress, advanced glycosylation end products, or DM-induced dyslipidemia. It is likely that all of these factors could have contributed in some degrees to the change in vascular reactivity. Although the patients with DM in this study had received perioperative oral hypoglycemic agents and/or insulin, a previous study in dogs found a similar increased 


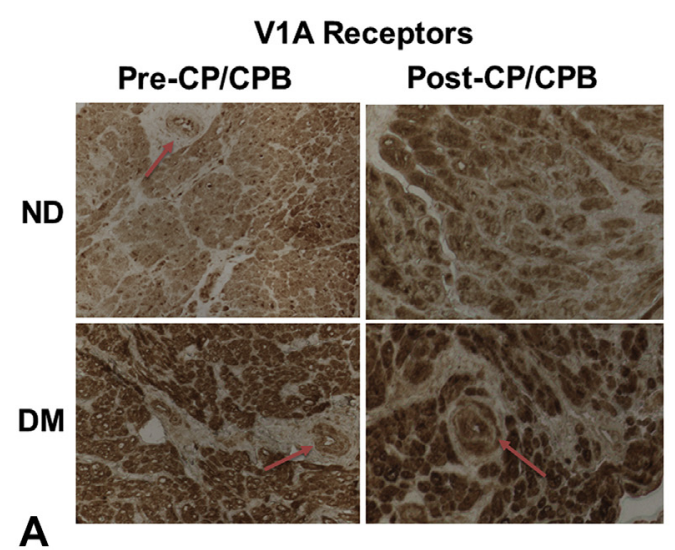

V1B Receptors

Pre-CP/CPB Post-CP/CPB
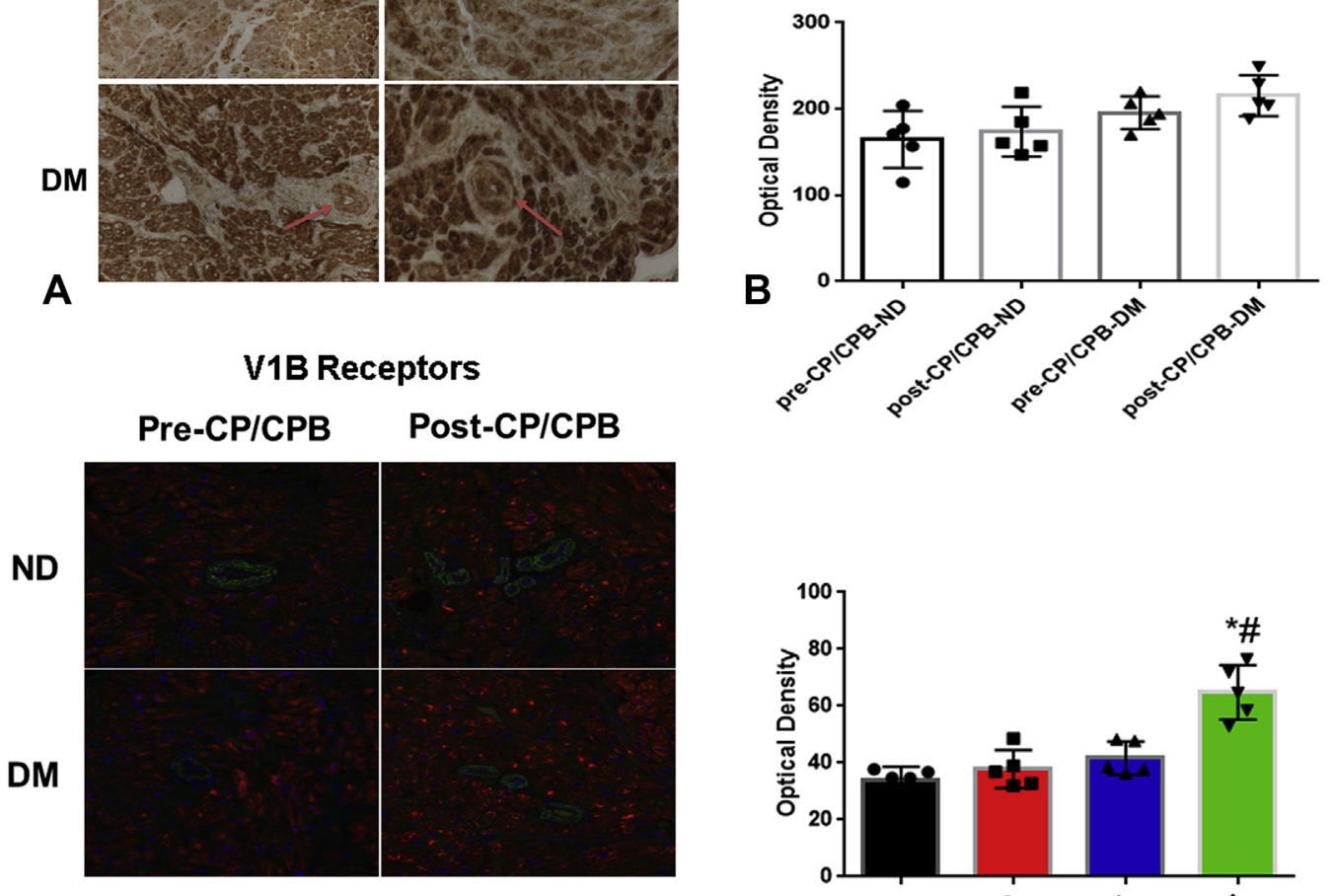

C

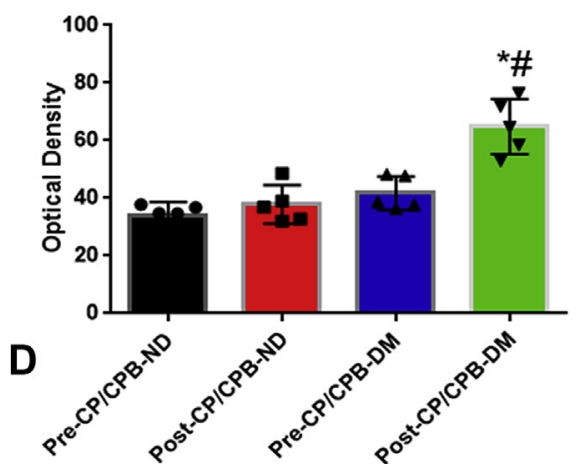

FIGURE 4. A, Immunohistochemical image of V1A in paraffin-embedded human atrial tissue slides from patients in the ND and DM groups. Red arrows show V1A signals in the atrial microvessels. B, Densitometric analysis of signal intensities. C, Immunofluorescence staining of V1B receptors in the embedded human atrial tissue slides from patients in the ND and DM groups before and after CP/CPB. D, Densitometric analysis of signal intensities. ${ }^{*} P<.05$ versus pre-CP/CPB-DM, \#P<.05 versus post-CP/CPB-ND; $\mathrm{n}=5$ /group, mean \pm standard deviation. V1A, Vasopressin $1 \mathrm{~A}$ receptor; $V 1 B$, vasopressin $1 \mathrm{~B}$ receptor; pre-CP/CPB-DM, before cardioplegia and cardiopulmonary bypass in patients with diabetes; post-CP/CPB-ND, after cardioplegia and cardiopulmonary bypass in patients without diabetes; $N D$, nondiabetic; $D M$, diabetes.

contractile response to vasopressin. In that study, the animals did not receive either insulin or hypoglycemic medications. ${ }^{11}$

Third, we did not measure blood vasopressin concentrations during cardiac surgery. This would have possibly increased the clinical impact of the study. Fourth, this study focused on the response of atrial microcirculation. These effects on the ventricular myocardium could be clinically more significant. Unfortunately, due to the nature of the study, it would be difficult to sample ventricular myocardium of our patients undergoing coronary artery bypass surgery. However, we feel comfortable generalizing our study to the ventricular myocardium based on previous studies in animals. In canine studies in which arterial microvessels were harvested from the ventricular myocardium, the investigators observed a similar increase in reactivity of the ventricular microvasculature to vasopressin after ischemia as was observed in the atrial microvasculature in the current study. ${ }^{11}$

In summary, we observed an increased coronary microvascular contractile response to vasopressin after cardiac surgery, associated with an increased expression of V1 receptors. These changes were more evident in patients with poorly controlled DM (Video 1). Thus, practitioners should be aware of the increased contractile response of coronary arterioles patients may have to vasopressin after cardiac surgery when considering administration of this drug. ${ }^{22,35-38}$ 


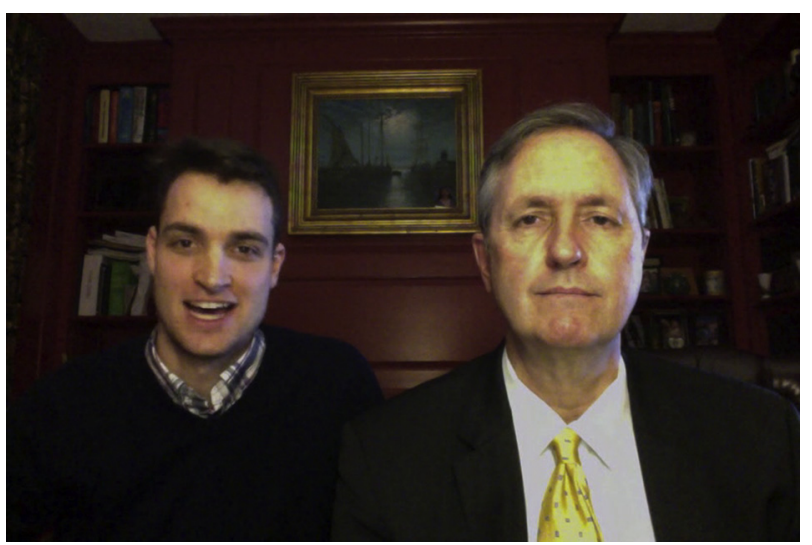

VIDEO 1. Vasopressin increased coronary arteriolar contraction in patients with diabetes after cardiac surgery. Video available at: https:// www.jtcvs.org/article/S0022-5223(18)31526-5/fulltext.

\section{Conflict of Interest Statement}

Authors have nothing to disclose with regard to commercial support.

We thank all the nurses, physician assistants, and perfusionists working in cardiac surgery at Rhode Island Hospital for collecting the tissue samples and recording patient characteristics. We also thank the nurses and physician assistants at Division of Cardiac Surgery of Rhode Island Hospital for collecting patient consent forms.

\section{References}

1. Haffner SM, Lehto S, Rönnemaa T, Pyörälä K, Laakso M. Mortality from coronary heart disease in subjects with type 2 diabetes and in nondiabetic subjects with and without prior myocardial infarction. N Engl J Med. 1998;339:229-34.

2. Thourani VH, Weintraub WS, Stein B, Gebhart SS, Craver JM, Jones EL, et al. Influence of diabetes mellitus on early and late outcome after coronary artery bypass grafting. Ann Thorac Surg. 1999;67:1045-52.

3. De Vriese AS, Verbeuren TJ, Van de Voorde J, Lameire NH, Vanhoutte PM. Endothelial dysfunction in diabetes. Br J Pharmacol. 2000;130:963-74.

4. Feng J, Liu Y, Chu LM, Clements RT, Khabbaz KR, Robich MP, et al. Thromboxane-induced contractile response of human coronary arterioles is diminished after cardioplegic arrest. Ann Thorac Surg. 2011;92:829-36.

5. Feng J, Chu LM, Dobrilovic N, Liu Y, Singh AK, Sellke FW. Decreased coronary microvascular reactivity after cardioplegic arrest in patients with uncontrolled diabetes mellitus. Surgery. 2012;152:262-9.

6. Feng J, Liu Y, Sabe AA, Sadek AA, Singh AK, Sodha NR, et al. Differential impairment of adherens-junction expression/phosphorylation after cardioplegia in diabetic versus non-diabetic patients. Eur J Cardiothorac Surg. 2015;49: 937-43.

7. Verma S, Maitland A, Weisel RD, Fedak PW, Li SH, Mickle DA, et al. Increased endothelin-1 production in diabetic patients after cardioplegic arrest and reperfusion impairs coronary vascular reactivity: reversal by means of endothelin antagonism. J Thorac Cardiovasc Surg. 2002;123:1114-9.

8. Feng J, Sellke F. Microvascular dysfunction in patients with diabetes after cardioplegic arrest and cardiopulmonary bypass. Curr Opin Cardiol. 2016; 31:618-24.

9. Khan TA, Bianchi C, Ruel M, Feng J, Sellke FW. Differential effects on the mesenteric microcirculatory response to vasopressin and phenylephrine after cardiopulmonary bypass. J Thorac Cardiovasc Surg. 2007;133:682-8.

10. Robich MP, Araujo EG, Feng J, Osipov RM, Clements RT, Bianchi C, et al. Altered coronary microvascular serotonin receptor expression after coronary artery bypass grafting with cardiopulmonary bypass. J Thorac Cardiovasc Surg. 2010;139:1033-40.

11. Sellke F, Quillen J. Altered effects of vasopressin on the coronary circulation after ischemia. J Thorac Cardiovasc Surg. 1992;104:357-63.
12. Novella S, Martínez AC, Pagán RM, Hernández M, García-Sacristán A, González-Pinto A, et al. Plasma levels and vascular effects of vasopressin in patients undergoing coronary artery bypass grafting. Eur J Cardiothorac Surg. 2007;32:69-76.

13. Masetti P, Murphy SF, Kouchoukos NT. Vasopressin therapy for vasoplegic syndrome following cardiopulmonary bypass. J Card Surg. 2002;17:485-9.

14. Darcy M. Treatment of lower gastrointestinal bleeding: vasopressin infusion versus embolization. J Vasc Interv Radiol. 2003;14:535-43.

15. Métais C, Li J, Li J, Simons M, Sellke FW. Serotonin-induced coronary contraction increases after blood cardioplegia-reperfusion. Circulation. 1999;100: III328-34.

16. Sabe AA, Potz BA, Elmadhun NY, Liu Y, Feng J, Abid MR, et al. Calpain inhibition improves collateral-dependent perfusion in a hypercholesterolemic swine model of chronic myocardial ischemia. J Thorac Cardiovasc Surg. 2016;151: 245-52.

17. Bax WA, Van der Graaf PH, Stam WB, Bos E, Nisato D, Saxena PR. [arg8] vasopressin-induced responses of the human isolated coronary artery: effects of non-peptide receptor antagonists. Eur J Pharmacol. 1995;285:199-202.

18. Sharshar T, Blanchard A, Paillard M, Raphael JC, Gajdos P, Annane D. Circulating vasopressin levels in septic shock. Crit Care Med. 2003;31:1752-8.

19. Bomberg H, Bierbach B, Flache S, Wagner I, Glaser L, Groesdonk HV, et al. Endothelin and vasopressin influence splanchnic blood flow distribution during and after cardiopulmonary bypass. J Thorac Cardiovasc Surg. 2013;145:539-47.

20. Hajjar LA, Vincent JL, Galas FRBG, Rhodes A, Landoni G, Osawa EA, et al. Vasopressin versus norepinephrine in patients with vasoplegic shock after cardiac surgery: the VANCS randomized controlled trial. Anesthesiology. 2017;126: 85-93.

21. Rurak D. Plasma vasopressin levels during hypoxaemia and the cardiovascular effects of exogenous vasopressin in foetal and adult sheep. J Physiol. 1978; 277:341-57.

22. Talbot MP, Tremblay I, Denault AY, Bélisle S. Vasopressin for refractory hypotension during cardiopulmonary bypass. J Thorac Cardiovasc Surg. 2000;120: 401-2.

23. Indrambarya T, Boyd JH, Wang Y, McConechy M, Walley KR. Low-dose vasopressin infusion results in increased mortality and cardiac dysfunction following ischemia-reperfusion injury in mice. Crit Care. 2009; 13:R98.

24. Bomberg H, Bierbach B, Flache S, Scheuer C, Novak M, Schafers HJ, et al. Vasopressin induces rectosigmoidal mucosal ischemia during cardiopulmonary bypass. J Card Surg. 2014;29:108-15.

25. Bankir L, Bardoux P, Ahloulay M. Vasopressin and diabetes mellitus. Nephron. 2001;87:8-18.

26. Trinder D, Phillips PA, Stephenson JM, Risvanis J, Aminian A, Adam W, et al. Vasopressin v1 and v2 receptors in diabetes mellitus. Am J Physiol. 1994;266: E217-23.

27. Feng J, Anderson K, Singh AK, Ehsan A, Mitchell H, Liu Y, et al. Diabetes upregulation of cyclooxygenase 2 contributes to altered coronary reactivity after cardiac surgery. Ann Thorac Surg. 2017;104:568-76.

28. Sabe AA, Dalal RS, Chu LM, Elmadhun NY, Ramlawi B, Bianchi C, et al. Preoperative gene expression may be associated with neurocognitive decline after cardiopulmonary bypass. J Thorac Cardiovasc Surg. 2015;149:613-23.

29. Sodha NR, Feng J, Clements RT, Bianchi C, Boodhwani M, Ramlawi B, et al. Protein kinase $\mathrm{c}$ alpha modulates microvascular reactivity in the human coronary and skeletal microcirculation. Surgery. 2007;142:243-52.

30. Khan TA, Bianchi C, Araujo EG, Ruel M, Voisine P, Li J, et al. Cardiopulmonary bypass reduces peripheral microvascular contractile function by inhibition of mitogen-activated protein kinase activity. Surgery. 2003;134:247-54.

31. Feng J, Chu LM, Nikola DN, Liu Y, Singh AK, Sellke FW. Decreased coronary microvascular reactivity after cardioplegic arrest in patients with poorly controlled diabetes. Surgery. 2012;152:262-9.

32. Sellke FW, Shafique T, Ely DL, Weintraub RM. Coronary endothelial injury after cardiopulmonary bypass and ischemic cardioplegia is mediated by oxygenderived free radicals. Circulation. 1993;88:II395-400.

33. Friedman M, Wang SY, Sellke FW, Cohn WE, Weintraub RM, Johnson RG. Neutrophil adhesion blockade with NPC 15669 decreases pulmonary injury after total cardiopulmonary bypass. J Thorac Cardiovasc Surg. 1996;111:460-8.

34. Wang SY, Friedman M, Johnson RG, Weintraub RM, Sellke FW. Adrenergic regulation of coronary microcirculation after extracorporeal circulation and crystalloid cardioplegia. Am J Physiol. 1994;267:H2462-70.

35. Papadopoulos G, Sintou E, Siminelakis S, Koletsis E, Baikoussis NG, Apostolakis E. Perioperative infusion of low-dose of vasopressin for prevention and management of vasodilatory vasoplegic syndrome in patients undergoing 
coronary artery bypass grafting — a double-blind randomized study. J Cardiothorac Surg. 2010;5:17.

36. Argenziano M, Chen JM, Choudhri AF, Cullinane S, Garfein E, Weinberg AD, et al. Management of vasodilatory shock after cardiac surgery: identification of predisposing factors and use of a novel pressor agent. J Thorac Cardiovasc Surg. 1998;116:973-80

37. Noto A, Lentini S, Versaci A, Giardina M, Risitano DC, Messina R, et al. A retrospective analysis of terlipressin in bolus for the management of refractory vasoplegic hypotension after cardiac surgery. Interact Cardiovasc Thorac Surg. 2009;9:588-92.
38. Colson PH, Bernard C, Struck J, Morgenthaler NG, Albat B, Guillon G. Post car diac surgery vasoplegia is associated with high preoperative copeptin plasma concentration. Crit Care. 2011;15:R255.

Key Words: cardioplegia, cardiopulmonary bypass, vasopressin, coronary arterioles, diabetes, microvascular reactivity 